\title{
Perspective
}

PERSPECTIVE Actualité en histoire de l'art

$2 \mid 2020$

Danser

\section{Vertige du corps : le cubisme tchèque et la danse}

Vertiginous Bodies: Czech Cubism and Dance

Im Rausch des Körpers: Der tschechische Kubismus und der Tanz

Vertigine del corpo: il cubismo ceco e la danza

Vértigo del cuerpo: el cubismo checo y la danza

\section{Petra Kolářová}

\section{(2) OpenEdition}

Journals

Édition électronique

URL : https://journals.openedition.org/perspective/21106

DOI : 10.4000/perspective. 21106

ISSN : 2269-7721

Éditeur

Institut national d'histoire de l'art

Édition imprimée

Date de publication : 30 décembre 2020

Pagination : 195-206

ISBN : 978-2-917902-90-5

ISSN : $1777-7852$

Référence électronique

Petra Kolářová, « Vertige du corps : le cubisme tchèque et la danse», Perspective [En ligne], 2 | 2020,

mis en ligne le 30 juin 2021, consulté le 30 juillet 2022. URL : http://journals.openedition.org/

perspective/21106; DOI : https://doi.org/10.4000/perspective.21106 


\title{
Vertige du corps : le cubisme tchèque et la danse
}

\author{
Petra Kolářová
}

À Vojtěch Lahoda (1955-2019)

Dans son texte La Création de la nouvelle figure dans l'art, Vojtěch Lahoda désigne le danseur ou la danseuse comme une des figures caractéristiques du cubisme tchèque, dans lesquelles la sensualité s'associe à la spiritualité ${ }^{1}$. Aux yeux des artistes qui se réunissent entre 1911 et 1913 au sein de la Skupina výtvarných umělců (le " Groupe des plasticiens ${ }^{2}$ »), la danse incarne une problématique de la représentation du corps en mouvement en même temps qu'elle matérialise une idée abstraite, voire spirituelle. L'architecte Vlastislav Hofman développe cette idée dans La Corporéité de la danse, en 1913 : "Le point de vue général sur la danse en tant qu'art créatif et art de la scène pourrait être guidé par certaines questions : l'utilisation de la propension du mouvement aux formes les plus pures, à l'effet sensationnel le plus vif, à la facilitation de la compréhension de l'espace et de la forme plastique dans la révélation des mouvements les plus insolites ${ }^{3}$. " Or, le cubisme tchèque, qui avait pour objectif de toucher tous les domaines des arts plastiques, y compris l'architecture et les arts décoratifs, et dont l'impact s'était étendu aussi sur la littérature, le cinéma et la musique, n'a jamais donné naissance à une forme cubiste en danse ${ }^{4}$. La danse a pourtant inspiré les cubistes tchèques. D'une part, ils ont représenté des impressions vécues en observant des performances dans des cabarets artistiques et populaires (comme celles de Sulamit Rahu ou d'Emča Revoluce) et, d'autre part, ils se sont inspirés des théories de la danse moderne (celles d'Émile Jaques-Dalcroze et de Rudolf von Laban). De la représentation de la danse concrète à une conception de la création artistique irriguée par une pensée chorégraphique, il s'agit ici d'étudier les relations à la danse de la peinture d'Otakar Kubín (1883-1969), de la sculpture d'Otto Gutfreund (1889-1927) et de l'architecture de Jiří Kroha (1883-1974).

En 1913, Hofman constate que " dans la danse, il est de plus en plus souvent question de l'espace et de ses changements ondoyants ${ }^{5}$ ". Il touche ici une problématique intrinsèque à la danse des premières avant-gardes : celle de la dématérialisation du corps au profit d'une composition spatiale, dynamique et abstraite. Gabriele Brandstetter définit en tant que " topos formula " des structures spatiales, comme la spirale ou le labyrinthe, que les danseuses et les danseurs d'avant-garde déployaient sur scène de manière à faire disparaître leur corps dans le mouvement. Ces structures représentent des formules 
dynamiques à la symbolique archétypale qui, de plus, peuvent être exploitées à travers plusieurs médias artistiques, de la danse à la peinture. Trouve-t-on, dans les œuvres plastiques des trois cubistes tchèques, ces topos formula, créées en dialogue direct ou indirect avec la danse ? Les sensations qu'elles provoquent chez les spectateurs sont-elles de même nature que celles suscitées par la danse ?

Le physiologue Jan Evangelista Purkinje, qui étudia au XIXe siècle les effets du vertige sur la perception humaine, a déterminé dans l'observation de la danse l'une des sources du changement d'état de conscience et de la perte d'équilibre ${ }^{7}$. De Loïe Fuller, qui provoqua, avec ses mouvements en spirale, des hallucinations chez le public ${ }^{8}$ à Mary Wigman, qui fascina la salle par son corps suspendu en extase ${ }^{9}$, la danse moderne suscita ce genre d'états, de l'étourdissement des sens à la transe, en engageant non seulement la vue mais aussi le sens kinesthésique du spectateur. Ces performances proposaient une expérience multisensorielle, dans laquelle le spectateur s'oubliait lui-même et se laissait mouvoir par la danse, vecteur de contenus spirituels ${ }^{10}$. Nell Andrew a récemment souligné la synergie entre la danse et les arts plastiques qui, à l'origine de l'abstraction, explorent parallèlement la kinesthésie ${ }^{11}$. Dans le cubisme tchèque, les œuvres plastiques de Kubín, de Gutfreund et de Kroha, créées au contact de la danse, font également appel aux sens proprioceptif et sensorimoteur du spectateur en provoquant des sensations qui troublent ses repères spatio-temporels, jusqu'à lui donner le vertige. À travers leurs œuvres picturales, sculpturales et architecturales respectives, nous montrerons comment, en employant des conceptions dynamiques du corps et de l'espace, ils ont provoqué des sensations proches du vertige chez le spectateur et, dans le monde déséquilibré, morcelé et changeant du début du $\mathrm{XX}^{\mathrm{e}}$ siècle, lui ont fait vivre une nouvelle union spirituelle avec la totalité du monde.

\section{Le danseur dans l'espace cosmique : la peinture d'Otakar Kubín}

En 1914, Otakar Kubín, connu en France sous le nom d'Othon Coubine, expose à la Galerie Der Sturm, à Berlin, une série de tableaux qui représentent des figures géométrisées aux gestes et aux postures énigmatiques, dont la Figure II (fig. 1) fait partie ${ }^{12}$. À cette époque, après une période expressionniste liée au groupe Osma (le groupe des " Huit ${ }^{13}$ "), il s'installe à Paris et développe une version personnelle du cubisme fondée sur la géométrisation radicale d'objets et de figures, réduits à une forme essentielle et plane ${ }^{14}$. De sa période cubiste, qui ne dure que deux ans, de 1913 à 1914, on connaît peu d'œuvres aujourd'hui ${ }^{15}$. Il ne reste que des fragments de l'ensemble d'une vingtaine de tableaux exposés à la Galerie Der Sturm, que l'on ne peut qu'approximativement rapprocher des titres que Kubín donne à ses œuvres ${ }^{16}$. Deux types de figures se dégagent de cet ensemble : d'une part, des figures " d'absorption ", enfermées sur elles-mêmes, aux gestes repliés contre leurs corps, comme la Figure $I^{17}$, se rattachant aux états de contemplation que les titres de tableaux Le Silence, L'Humilité ou Le Savant suggèrent; et, d'autre part, des figures " d'action » dont les gestes et les postures se déploient dans l'espace, comme la Figure II, exprimant des sentiments de révolte tels que les évoquent les noms d'œuvres comme L'Orgueil, La Colère ou Le Guerrier. Entre le repos et l'action, les figures de Kubín contiennent un potentiel de mouvement qui se manifeste dans la " chorégraphie " de leurs postures et de leurs gestes et qui dénote une ressemblance avec la danse ${ }^{18}$. Dès ses premiers voyages à Paris, en 1905 et 1908, Otakar Kubín montre en effet de l'intérêt pour le monde du café-concert et pour ses formes de spectacle, dont la danse ; Le Music-hall Bobino ${ }^{19}$, qu'il peint en 1910, témoigne de l'attention portée par l'artiste à l'expression du corps sur scène. Elle représente 
un danseur de cabaret, vêtu d'un frac noir et d'un chapeau haut-de-forme, dont la posture et les gestes sont proches de la Figure II $^{20}$. Or, si les cafés-concerts parisiens représentaient un vivier dans lequel Kubín, comme d'autres artistes d'avant-garde, recherchait une source authentique de l'expression ou du " geste primitif ", les analogies à la danse dans son œuvre se révèlent plus complexes.

On y dénote aussi des parentés avec les idées du chorégraphe Rudolf von Laban (1879-1958), qui développe à partir des années 1910 une nouvelle conception de la danse fondée sur les rapports entre le corps et l'espace ${ }^{21}$. Dans son premier livre, Le Monde du danseur (Die Welt des Tänzers, 1920), Laban met en avant une notion de la tension corporelle qui est à l'origine $\mathrm{du}$ geste du danseur ${ }^{22}$. Le corps, d'abord soumis à la pesanteur, propulse bras et jambes en dehors de son centre de gravité dans les quatre directions de l'espace : le mouvement du danseur est alors conçu comme une série de changements de tension corporelle qui détermine le positionnement du corps

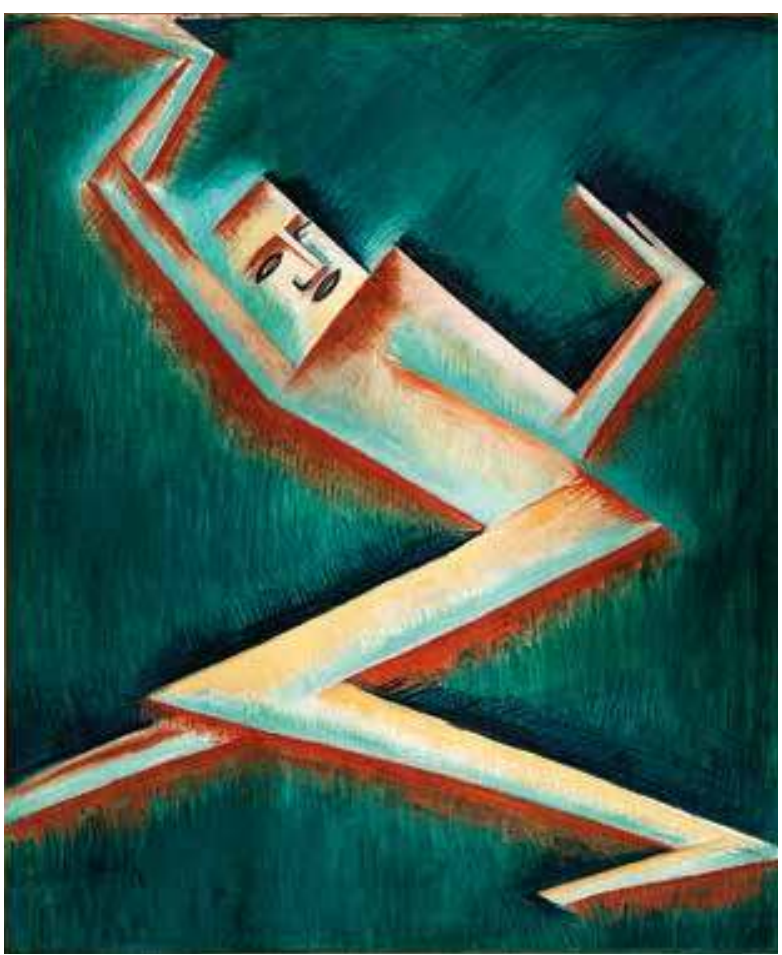

1. Otakar Kubín, Figure II, 1913-1914, Prague, Galerie nationale. dans l'espace. Nous pouvons emprunter la terminologie de Laban pour interpréter la pose de la Figure II : elle traduit " une tension corporelle " qui se projette en dehors, déployant ses membres au contact de l'espace qui l'environne ${ }^{23}$. Représentée dans un équilibre précaire, la figure lève les bras comme pour repousser l'espace qui l'entoure. Placée sur un fond vert foncé, elle est rendue par des couleurs claires ; la lumière intérieure qui semble émaner d'elle nous renseigne sur la nature spirituelle de cette tension qui l'anime du dedans. Alimentés par les mêmes sources philosophiques et esthétiques centre-européennes et proches de $l^{\prime}$ expressionnisme allemand ${ }^{24}$, le peintre et le chorégraphe partagent les mêmes convictions sur les fondements spirituels de l'art : la forme artistique est créée par l'action de l'esprit sur la matière, dont le résultat est une forme géométrique, abstraite ${ }^{25}$. Comme dans les figures de Kubín, les dessins de Laban montrent, à la même époque, des corps aux gestes géométrisés, animés de l'intérieur ${ }^{26}$. Nourris par l'ésotérisme et l'anarchisme ${ }^{27}$, à la recherche d'un renouveau spirituel et de la création d'un homme nouveau, ils traitent tous les deux, dans leurs œuvres respectives, des mythes archaïques d'anciennes religions mettant en scène l'homme dans un espace cosmique, aux prises avec les forces spirituelles qui agissent sur lui ${ }^{28}$. La Figure II représente, dans ce contexte, un héros mythique qui se soulève contre le monde, comme le guerrier slave Svatogor, l'un des titres que Kubín choisit pour ses tableaux ${ }^{29}$, et s'inscrit ainsi parmi les œuvres de l'artiste qui explorent l'idée de la révolte contre les dieux ${ }^{30}$.

Kubín développe le thème de la résistance de l'homme dans la série de six gravures sur bois intitulée Les Misères humaines, publiée en 1914 en deux versions, tchèque et française $^{31}$, où elle est associée au poème Le Baiser du père d'Otto Klein ${ }^{32}$, traduit en 

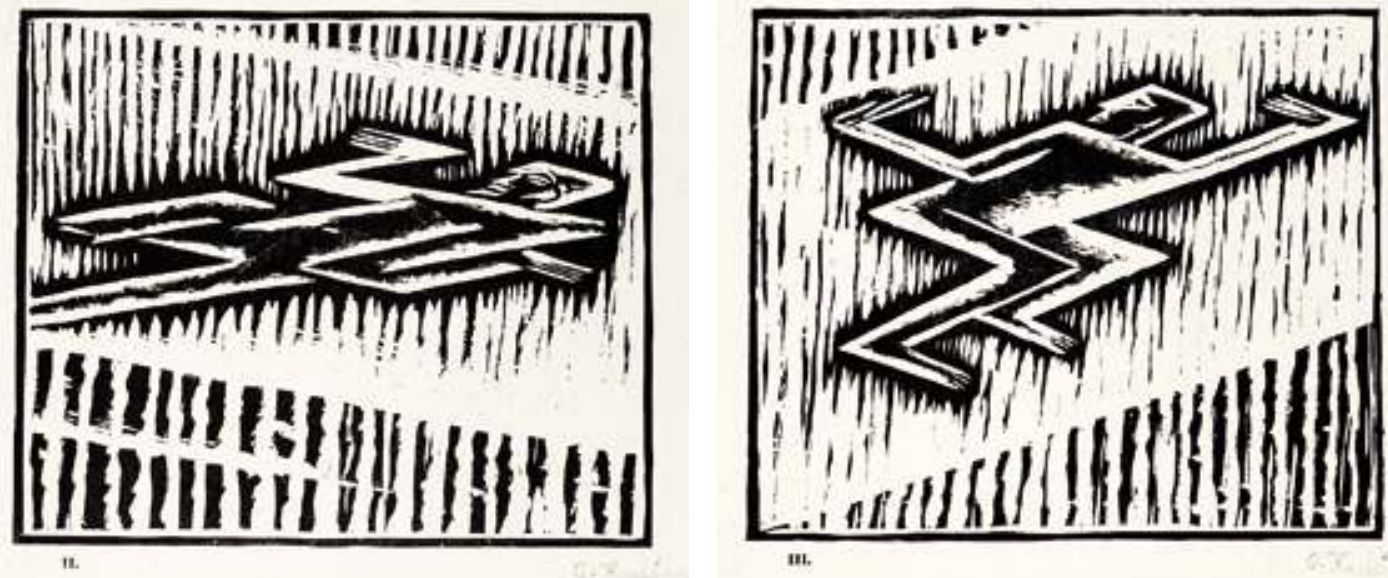

2a-d. Otakar Kubín, Les Misères humaines, 1914, Prague, Galerie nationale. français par Blaise Cendrars. Le peintre et le poète, qui « traversèrent ensemble les joies et les malheurs des années de guerre ${ }^{33}$ ", proposent dans leur opus commun une méditation sur le destin de l'homme moderne. Le poème de Klein raconte le périple sym-

bolique d'un jeune héros qui parcourt le monde en bateau ; battu par la tempête, il réussit à s'en sortir pour rejoindre le paysage paradisiaque de son enfance. Kubín illustre de manière libre les vers en représentant, dans une série de quatre figures (fig. 2a-d), l'homme qui se bat contre la misère, d'après le titre qu'il donne à son cycle : d'abord dominé par son malheur, l'homme se lève progressivement et reprend des forces pour échapper à sa condition et retrouver le paradis perdu. Le peintre exprime le réveil du héros qui s'anime à travers la représentation d'un conflit de forces entre le corps et l'espace, déjà présent dans la Figure II : tandis que, sur la première estampe de la série, la figure apparaît littéralement écrasée sur le plan de l'image en deux dimensions (fig. 2a), sur les images suivantes elle grandit et s'émancipe de l'étreinte de son environnement jusqu'à se libérer de l'emprise des forces du destin (fig. 2d). Kubín représente la figure dans un espace où les lois naturelles de la pesanteur sont remplacées par celles de forces qui agissent en oblique, dans un espace vacillant où les corps perdent leur équilibre. C'est un espace métaphysique que le cinéma expressionniste allemand saura si bien représenter ${ }^{34}$. Par le biais de ces procédés plastiques, Kubín inscrit " la tension corporelle ", chère à Laban, dans la posture de ses figures qui, par leur élan spirituel, semblent propulser leur corps dans l'espace et le repousser pour se mouvoir en toute liberté. En regardant la série des figures de Kubín, le spectateur, quant à lui, s'identifie progressivement à leur élan kinésique en activant en lui une force morale et spirituelle de résistance dans un monde qui chavire vers la guerre.

\section{La danse des surfaces : la sculpture d'Otto Gutfreund}

Otto Gutfreund (1889-1927) fut le seul sculpteur du Groupe des plasticiens et l'un des premiers artistes à développer, parallèlement à Pablo Picasso, le cubisme dans la sculpture $^{35}$. Dans le texte théorique Plocha a prostor ( « La surface et l'espace ») qu'il publie 

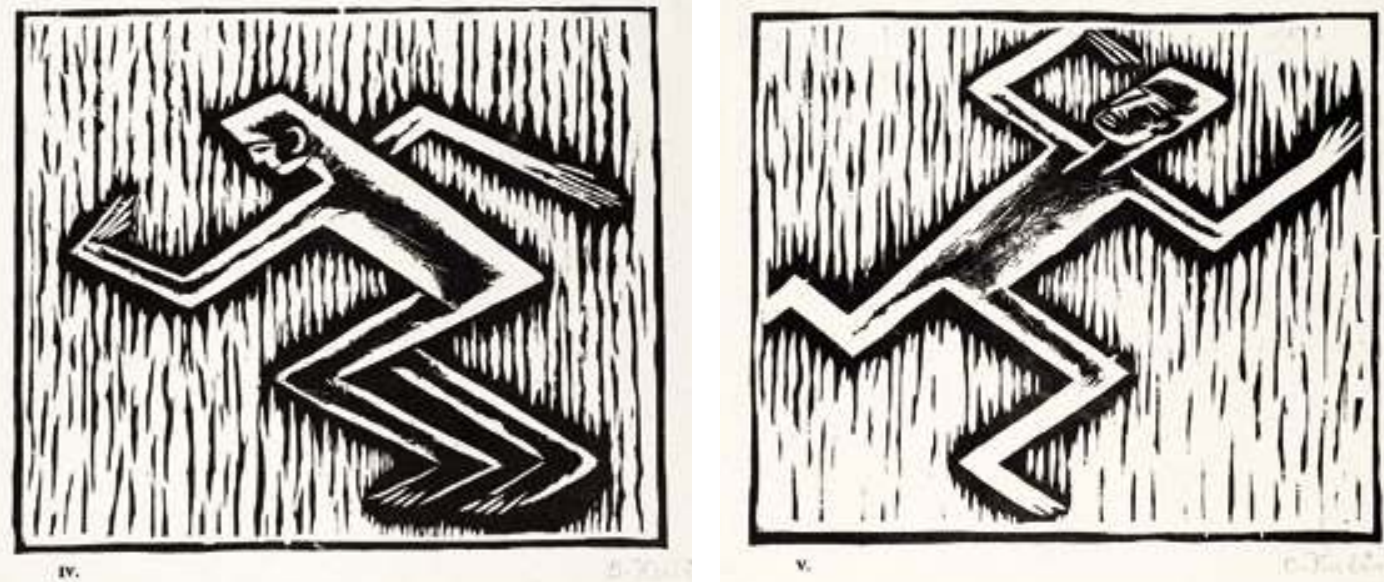

en $1913^{36}$, la référence à la danse joue un rôle important. C'est à Paris, à l'académie de la Grande Chaumière où il étudie avec Antoine Bourdelle entre 1909 et 1910, qu'il rencontre la problématique de la représentation de la danse. Après son retour à Prague à l'automne 1910, Gutfreund se souvient de la leçon de Bourdelle, qui admirait la danseuse Isadora Duncan et l'a dessinée de nombreuses fois, en représentant une danseuse du ventre, nommée Sulamit Rahu, qu'il a vue au cabaret praguois La Lucarne ${ }^{37}$. Le corps sensuel qu'il dessine montre l'engouement du jeune sculpteur pour le primitivisme tel que l'incarne non seulement cette danse venue d'ailleurs, mais aussi la sculpture dite nègre qu'il découvre lors de son séjour à Paris. D'une part, Gutfreund associe la danse à l'érotisme : " À l'origine, la danse, dit-il, était l'expression des désirs charnels, dont l'exemple typique est la danse de Salomé qui, comme la plupart des danses orientales, se présente presque comme un acte sexuel. [Elle représente] des mouvements réalistes, accomplis en rythme ${ }^{38}$. " Dans le domaine de la sculpture, d'autre part, c'est l'art nègre qui se distingue en ce que, dans ses ouvres, "la figuration du corps charnel est aussi forte, dans sa puissance expressive, que celle de la danse orientale ${ }^{39}$ ». Or, il postule que ces deux arts doivent dépasser leur " stade primitif " pour exprimer des émotions par des moyens plus abstraits.

Selon Gutfreund, le rythme et la dynamique sont les moyens abstraits de la danse. Le danseur reprend ces procédés formels de la musique et s'en sert pour exprimer les émotions dans une composition de mouvements : "Le danseur, dit-il, s'inspire de la musique et matérialise des états d'âme que la musique éveille en lui, il transporte ceux-ci dans le réel et crée, à partir d'eux, un art saisissable par l'œil ${ }^{40}$. " À la même époque, Émile Jaques-Dalcroze, qui donna à Prague deux conférences en 1911 et en $1912^{41}$, soutenait l'existence d'une relation étroite entre les mouvements du corps et les rythmes musicaux. Ses idées sur la gymnastique rythmique circulaient dans le milieu des cubistes tchèques $^{42}$, où la notion du rythme fut discutée dans l'architecture et les arts décoratifs ${ }^{43}$. Otto Gutfreund, qui jouait du piano et fréquentait des musiciens réunis autour du Groupe des plasticiens ${ }^{44}$, n'est pas resté indifférent aux idées du compositeur et chorégraphe suisse, dont on entend des échos dans sa théorie de la sculpture cubiste. La conception dalcrozienne de " la plastique animée " se fonde sur la transformation du rythme musical par " le sens musculaire " du danseur en une série de mouvements dans l'espace. Elle suggère une possibilité de traduire les rythmes musicaux, perceptibles dans le temps, dans une composition spatiale et dynamique, créée par un corps en mouvement ${ }^{45}$. Gutfreund 
opère la même transposition du rythme et de la dynamique dans une composition spatiale immobile : en transformant le volume compact de la sculpture en un système de surfaces, il introduit le rythme dans l'agencement des plans spatiaux. Il expérimente cette conception d'abord dans le dessin, quand il réalise une série de figures construites par des plans superposés. L'étude de 1914 (fig. 3) représente une figure féminine dont le corps est créé par un assemblage de surfaces. Le geste du bras levé avec une main tendue en arrière traduit un mouvement de rotation. Elle ressemble à une marionnette dont les mouvements sont devenus artificiels, à un homme-machine qui anticipe le canon mécanique créé par Oskar Schlemmer dans les années $1920^{46}$. C'est pendant la Première Guerre mondiale que Gutfreund applique sa conception de la sculpture en tant que système dynamique de plans, sous la forme de sculptures de bois, comme La Femme assise de 1916 (fig. 4), une conception déjà définie en 1913 :

\begin{abstract}
La surface mouvante, écrit-il, est un volume en train de se créer, ce n'est plus une forme mesurable par l'intellect. La fonction de cette forme est transmise à la surface mouvante, et la sculpture n'est plus un temps arrêté, transposé en espace, mais l'expression du devenir continuel, du mouvement incessant dont le rythme est identique à celui du processus intellectuel de création, avant que l'idée ne se soit stabilisée sous forme d'image. [...] La sculpture n'est plus un conglomérat solide de volumes que l'on décèle par observations successives, un fragment de temps pétrifié, mais un ondoiement continuel de plans, une illusion de volumes ${ }^{47}$.
\end{abstract}

3. Otto Gutfreund, Figure féminine, 1914, Brno, galerie de la Moravie.

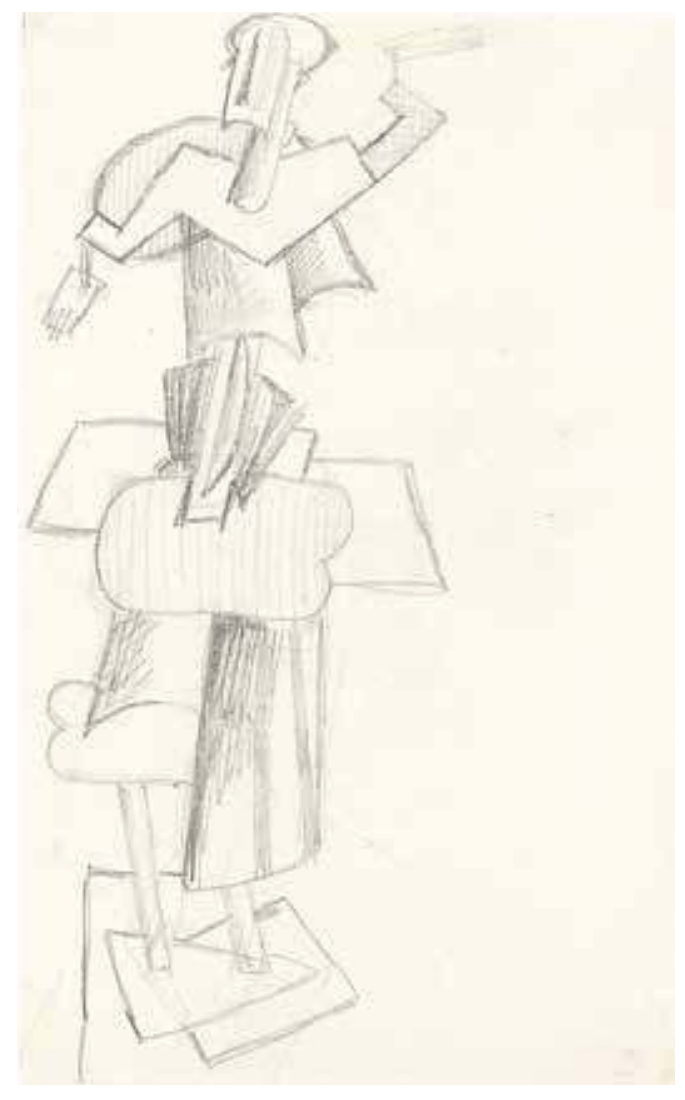

Sa sculpture est désormais fondée sur une dynamique des surfaces qui forment, par leur mouvement, le volume de l'œuvre. Influencé par la philosophie d'Henri Bergson, il considère le temps comme une durée indivisible qui ne peut être saisie que par l'intuition et qui se traduit par un mouvement continuel dans l'espace ${ }^{48}$. Comme l'a mis en avant Alena Pomajzlová ${ }^{49}$, on peut rapprocher la théorie de Gutfreund de la sculpture d'Umberto Boccioni (1882-1916), également partisan des idées de Bergson. Mais contrairement au futuriste italien, il n'emploie pas d'élément cinétique dans la sculpture pour exprimer le mouvement : s'inspirant de la conception bergsonienne du temps, il introduit le mouvement dans la durée de la perception de l'œuvre d'art.

Il revient de nouveau à la danse pour souligner l'aspect temporel du processus de l'observation de la sculpture, comme s'il s'agissait d'une performance ayant lieu devant le spectateur:

Les mouvements du danseur sont progressifs, l'un se dissout dans l'autre sans retour, le spectateur reçoit ces mouvements l'un après l'autre. Le sculpteur confie cette activité musculaire du danseur au spectateur, il contraint le spectateur, ou du moins son œil, à tourner, le spectateur ne reçoit les images de l'œuvre d'art qu'il interroge que successivement. [Le sculpteur] oblige l'œil du spectateur à effectuer un saut plus ou moins grand dans la profondeur, selon les proportions spatiales de la sculpture ${ }^{50}$. 


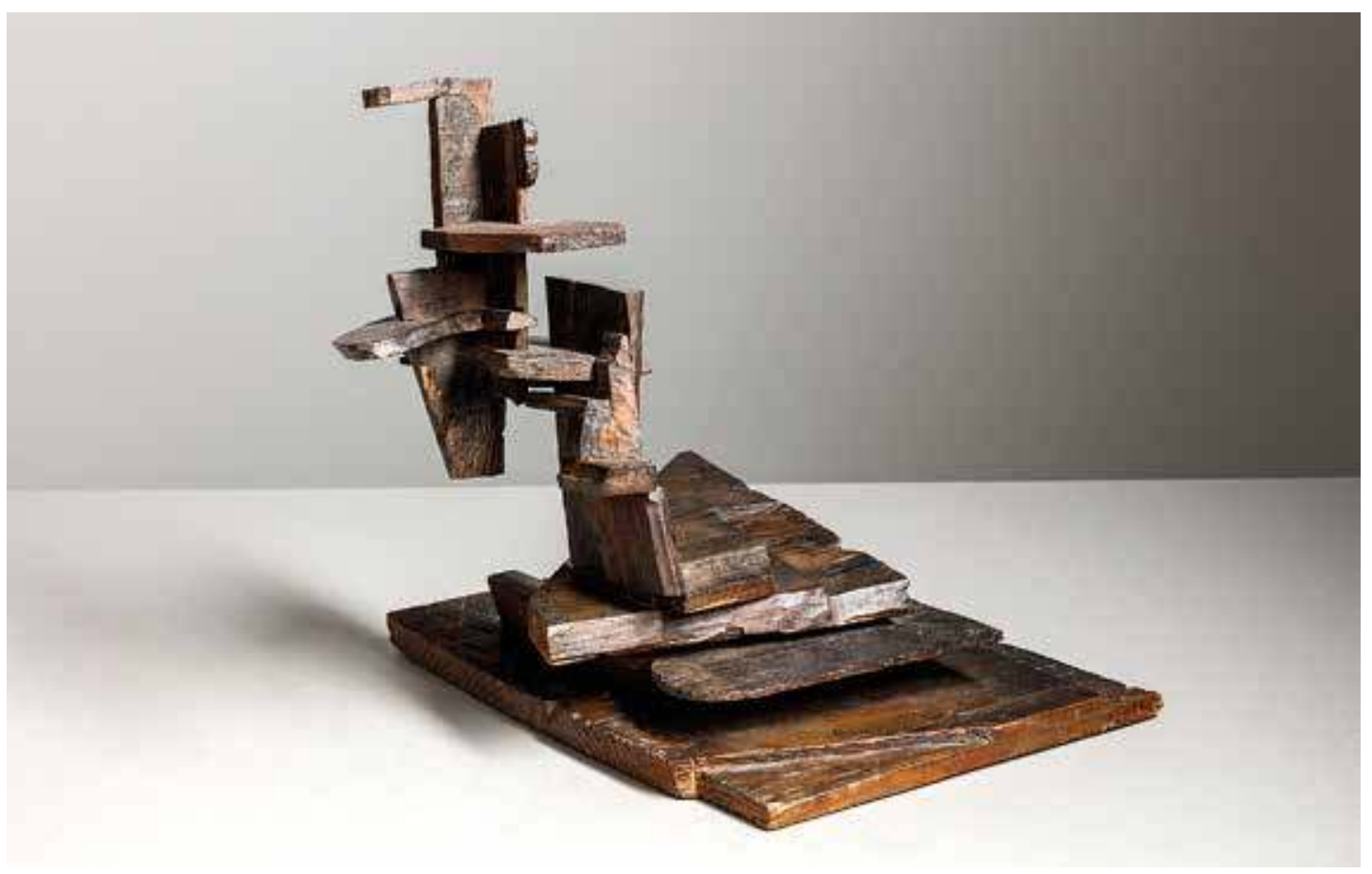

En inversant la mobilité du spectateur et de l'œuvre d'art, Gutfreund met l'accent sur la perception kinesthésique de 4 Otto Gutfreund, La Femme assise, 1916, Prague, Galerie nationale. la statue. Comme dans " la plastique animée " de JaquesDalcroze, le spectateur observe la sculpture non seulement par son regard, mais aussi grâce à son " sens musculaire ", qui lui permet de transformer le rythme des plans spatiaux en une sensation de mouvement. C'est en observant la structure dynamique des plans de La Femme assise, dont les formes anthropomorphes ont déjà complètement disparu, que le spectateur restitue " la danse des surfaces" et la rend vivante à ses yeux.

Or, le mouvement que la sculpture de Gutfreund suscite chez le spectateur est celui de la spirale ascendante que l'on retrouve déjà dans la danse du tournant du siècle, comme dans les mouvements aux effets hypnotiques de Loïe Fuller ${ }^{51}$. Le centre de gravité de La Femme assise est décentré, de telle sorte qu'une longue observation de cet " ondoiement continuel des plans " puisse procurer un sentiment de vertige au spectateur. Pour Otto Gutfreund, ce sentiment est lié à une expérience métaphysique : " Le vertige est la libération de notre soi et, en même temps, la prise de conscience de l'univers ${ }^{52}$. " En plaçant le spectateur devant une sculpture dont les formes en mouvement provoquent la perte de l'équilibre, il veut lui faire ressentir les rythmes de l'univers.

\section{La danse de l'espace : l'architecture de Jiří Kroha}

L'architecture cubiste, directement liée à la danse, n'apparaît qu'après la Première Guerre mondiale. C'est le jeune architecte Jiř́ Kroha (1883-1974) ${ }^{53}$ qui créa, en 1919, le décor du café Montmartre à Prague. Le lieu avait déjà une riche histoire nocturne : fondé en 1911 par l'ancien typographe, chansonnier, acteur et entrepreneur Josef Waltner (1883-1961), 


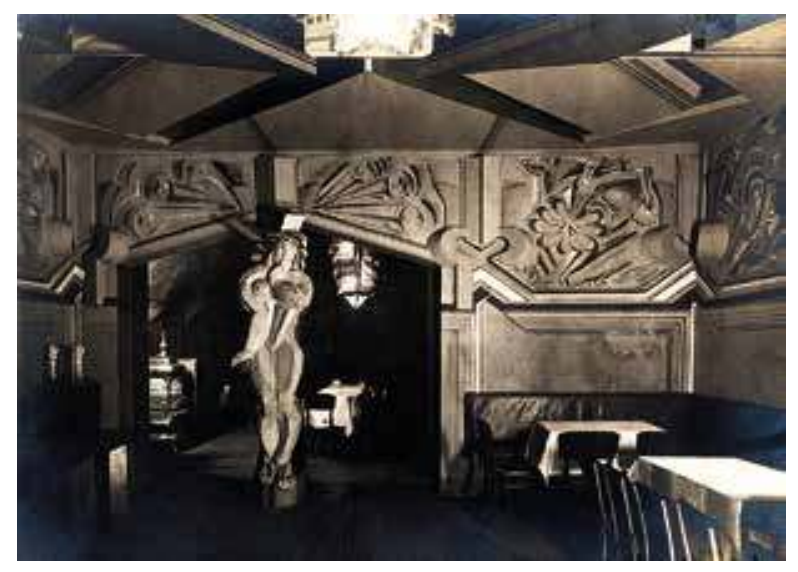

5. Jiří Kroha, Le café Montmartre à Prague - la salle centrale avec la sculpture d'Ève, 1920, Musée national, département du Théâtre. le café Montmartre ${ }^{54}$, nommé d'après la butte parisienne, devint un lieu de la vie de bohême praguoise où se rencontraient les artistes et les poètes tchèques et allemands. Parmi les habitués, on comptait les écrivains Jaroslav Hašek, František Langer, Franz Kafka, Max Brod ou Egon Erwin Kisch ${ }^{55}$. Mais le café était avant tout réputé pour la danse : c'est ici que le tango fut pratiqué à Prague pour la première fois.

Les trois salles du café, de taille différente, ont été, entre 1912 et 1919, plusieurs fois réaménagées. En 1914, Vratislav Hugo Brunner orne la salle principale avec Les Sept Péchés capitaux, les fresques peintes en couleurs sombres qui lui ont donné son nom : l'Enfer ${ }^{56}$. En 1918, l'aménagement de la salle mitoyenne, appelée plus tard « le Ciel » en raison de ses couleurs claires (fig. 5), a été

confié à Jiří Kroha. Le plafond à caissons aux formes cubistes y dominait l'espace, les consoles anguleuses rythmaient les murs décorés par des fresques représentant des danseuses (fig. 6) ${ }^{57}$. Une sculpture d'Ève aux formes dynamiques gardait l'entrée de "l'Enfer", éclairée par une lampe cubiste, créée également par l'architecte. Kroha aménagea aussi la dernière pièce du café, "l'Éden », utilisée par Josef Waltner pour ses événements privés. Le café que nous connaissons aujourd'hui grâce aux esquisses ${ }^{58}$ et aux photographies de l'époque est le seul projet visionnaire que l'architecte Jiří Kroha ait réalisés9 ; il représentait une œuvre unique, créée dans un style cubo-futuriste que nous ne pouvons comparer qu'avec peu de réalisations contemporaines ${ }^{60}$.

Au café Montmartre, Jiří Kroha a développé une nouvelle conception de l'espace qu'il présente également dans un texte de $1919^{61}$ : une conception vitaliste d'un espace doté de la qualité du vivant et qui s'actionne au contact de la matière. Il considère l'espace et la matière comme deux éléments de même nature qui « s'interpénètrent, se succèdent, se renouvèlent de manière incessante $[. .$.$] ce qui les rend justement durables et vivants { }^{62}$ ". La rencontre de ces deux éléments produit des formes dynamiques et abstraites dans lesquelles se cristallise une idée plastique. Jiří Kroha renoue avec l'idée, développée par l'architecte cubiste Pavel Janák, de la domination de l'esprit sur la matière ${ }^{63}$, en l'appliquant de manière encore plus assidue dans son œuvre : ses formes anguleuses découpent l'espace, tandis que celui-ci semble pénétrer la matière et y creuser des formes en profondeur ${ }^{64}$. Or, si le plafond et une partie supérieure des murs constituent un domaine où "l'idée plastique créatrice pure s'exprime sans compromis ${ }^{65}$ " et qui appartient aux formes cubistes, la partie inférieure des murs et le sol s'adaptent aux mouvements de l'homme, et peut être dédiée à la danse. Ces deux parties forment ensemble un seul espace unique, où la danse et l'architecture sont indissociables.

Jiří Kroha évoque, dans ses souvenirs, "le tango dans ses nuances, ses formes, ses mouvements, et ses gestes Art nouveau souples, à la langueur provocante ${ }^{66}$ " représenté dans les fresques de Vratislav Hugo Brunner sur les murs de la salle de l'Enfer. Outre le tango, d'autres danses populaires comme la danse apache, la danse de l'ours, du singe ou la danse d'épileptiques ${ }^{67}$ étaient pratiquées dans le café ${ }^{68}$. Leurs mouvements saccadés et " primitifs " n'évoquaient plus la fluidité, mais une ligne rompue en zigzag qui 
s'apparentait aux formes anguleuses de la salle aménagée par Kroha. Pour concevoir le projet, Jiří Kroha, visiteur assidu du lieu, s'imprégna des rythmes et des formes de ces danses qui ont laissé une empreinte dans son œuvre. Comme les autres habitués du café, il était fasciné par la danse d'Emča Revoluce qui était, loin des conventions, caractérisée par « un mouvement fou, spontané et insensé ${ }^{69}$ ", par laquelle elle " faisait tourbillonner, virevolter et [...] se déchaîner la salle " de l'Enfer au point de faire danser les fresques de Brunner elles-mêmes ${ }^{70}$. Les fresques de Kroha traduisent l'hilarité de sa danse frénétique, dans laquelle un nouveau corps expressionniste a été mis en scène.

En concevant la salle du Ciel avec des couleurs claires et des formes rythmiques et dynamiques, l'architecte voulait y induire une ambiance nouvelle, celle de " la révolte de la jeunesse [...] et la manifestation de sa liberté ${ }^{71} »$. Même la danse y est devenue, selon ses mots, "plus allègre, plus joyeuse et plus optimiste ${ }^{72} »$. Les fresques des danseuses

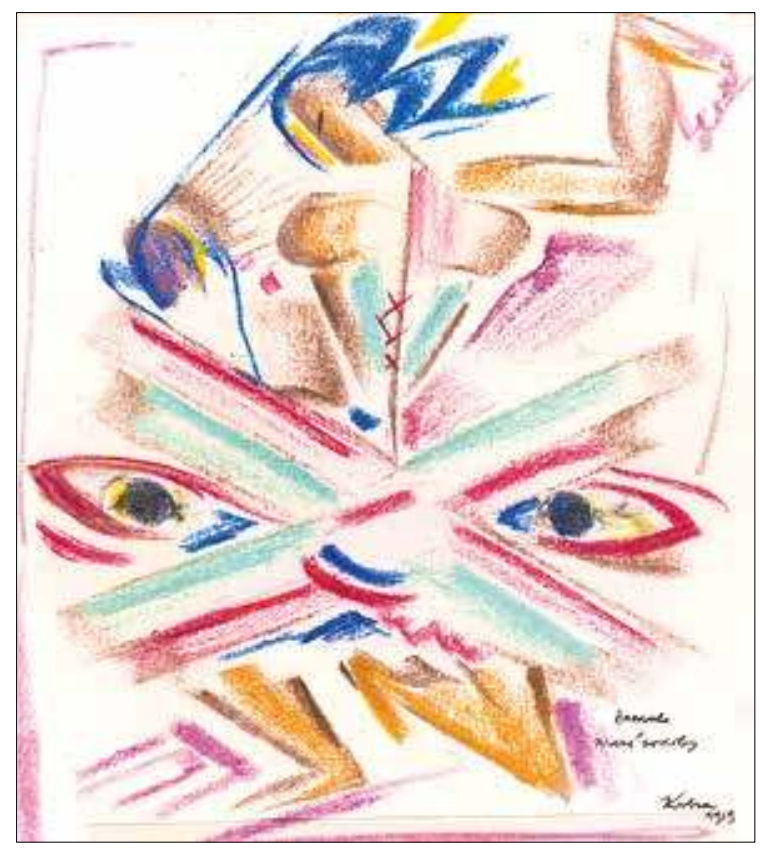

6. Jiří Kroha, Le café Montmartre à Prague - projet de la décoration murale (Le miroir cache la vraie face), 1919, Brno, musée de la Ville. portaient des noms qui parodiaient la morale bourgeoise ${ }^{73}$. Leur symbolique allait de pair avec celle de la dernière salle du café, l'Éden, où Josef Waltner célébrait " des messes noires " devant un autel cubiste décoré par un cochon rouge entouré de piles de billets, symbole de la bourgeoisie capitaliste ${ }^{74}$. Un esprit anarchique de révolte contre les conventions sociales et artistiques régnait au café Montmartre, lieu carnavalesque où l'on tombait le masque du quotidien et, bouleversant l'ordre ancien, où l'on vivait l'espoir d'un monde meilleur. Or, c'est l'espace architectural conçu par Kroha qui permettait aux visiteurs de sortir de leurs repères quotidiens. En entrant dans le café, ils étaient entraînés dans un tourbillon de sensations provoquées par la synergie des différents arts. Entre l'architecture et la danse, la poésie et la musique, ils participaient à une expérience multisensorielle, proprioceptive voire synesthésique, où les formes, les couleurs, les tons et les odeurs s'unissaient dans une œuvre d'art total. Animé par le rythme même de l'architecture, le corps des danseurs s'estompait dans des formes immatérielles et abstraites, en procurant aux spectateurs " les sensations envoûtantes d'un tourbillonnement écliptique de cercles vaguement perçus ${ }^{75}$ ". D'après les souvenirs de l'architecte, le café Montmartre fut un lieu où « les gens vivaient intellectuellement plus qu'ils ne se dépensaient physiquement ${ }^{76}$ ". Plus que de la corporéité, il était question des émotions, des relations et des idées ; l'espace architectural qui y fut créé les faisait ressortir encore davantage, en exerçant par son dynamisme une influence directe sur le public. Les visiteurs du café devenaient ainsi les acteurs involontaires de son architecture labyrinthique, conçue par Kroha comme une partie intégrante du "grand espace cosmique ${ }^{77}$ ». En s'abandonnant aux rythmes de la musique, de l'architecture et des corps dansants, les spectateurs perdaient leurs repères spatio-temporels et vivaient une expérience proche du vertige : ils entreprenaient un voyage initiatique et spirituel dans l'espace du café, à l'image de l'univers. 


\section{Petra Kolářová}

Petra Kolářová est docteure en histoire de l'art (université Paris 1 - Panthéon-Sorbonne ; Univerzita Karlova, Prague) et conservatrice au département des Arts graphiques à la Galerie nationale de Prague. Ses recherches ont porté sur les figures du corps au croisement des arts du spectacle et des arts plastiques dans les œuvres d'Étienne Decroux et de Jerzy Grotowski. Le présent article s'inscrit dans son projet actuel sur l'art tchèque et la danse (1880-1940).

\section{NOTES}

Le présent article a été préparé dans le cadre du soutien du ministère de la Culture de la République tchèque pour le développement conceptuel des institutions de recherche mené à long terme (DKRVO).

1. Vojtěch Lahoda, "The Creation of a New Figure in Art », dans Jiří Švestka, Tomáš Vlček (dir.), Czech cubism 1909-1925: Art, Architecture, Design (Düsseldorf / Stuttgart, 1991), Prague, Modernista, 2006, p. 334.

2. Les membres du groupe étaient, parmi d'autres : les peintres Emil Filla, Bohumil Kubišta, Antonín Procházka, Vincenc Beneš et Otakar Kubín, le sculpteur Otto Gutfreund, les architectes Pavel Janák, Josef Gočár, Josef Chochol et Vlastislav Hofman ; ils ont publié Umělecký měsícník [La Revue mensuelle artistique]. Voir Miroslav Lamač, Cubisme tchèque, Paris, Flammarion, 1992 ; Vojtěch Lahoda, Český kubismus, Prague, Brána, 1996.

3. "Všeobecné stanovisko k tanci jako k tvořivému umění a $k$ scénickému předvedení mohlo by se řídit dle určitých otázek: využití schopnosti pohybu k nejjednodušší formě, k nejostreješímu sensačnímu účinu, k usnadnění prostorového chápání, plastiky ve zjevování neobvyklých pohybů. » Voir Vlastislav Hofman, "Tělesnost tance », dans Volné směry, vol. XVII, 1913, p. 89 (les traductions du tchèque sont de l'auteure et de Lara Bonneau, sauf mention contraire).

4. La danse moderne tchèque ne s'est développée qu'après la Première Guerre mondiale ; voir Ivana Kloubková, Výrazový tanec v ČSR. Praha, Brno, 19181945, Prague, éditions SPN, 1989.

5. «[S]tále hojněji je tanec záležitostí představy prostoru a jeho vlnivých přeměn », voir Hofman, 1913, cité n. 3, p. 88.

6. Gabriele Brandstetter, Poetics of Dance. Body, Image and Space in the Historical Avant-Gardes (Francfortsur-le-Main, 1995), Oxford, Oxford University Press, 2015, p. 257-267.

7. Johann Purkinje, Beiträge zur Kenntniss des Sehens in subjektive Hinsicht, Prague, 1819, cité dans Lada Hubatová-Vacková, Vnitřní zrak. Jan Evangelista Purkyně, laboratoř vizuality a moderní umění, Prague, Centre d'études théoriques, 2005, p. 25 [en ligne, URL : http:// www.cts.cuni.cz/soubory/reporty/CTS-05-05.pdf].
8. Pascal Rousseau, "Corps fluidiques : danse, hypnose, et médiumnisme au passage du siècle », dans Christine Macel, Emma Lavigne (dir.), Danser sa vie. Art et danse de 1900 à nos jours, cat. exp. (Paris, Centre Pompidou, Musée national d'art moderne, 2011-2012), Paris, Éditions du Centre Pompidou, 2011, p. 98-103.

9. Sabine Huschka, «Pina Bausch, Mary Wigman and the Aesthetic of "Being Moved" », dans Susan Manning, Lucia Ruprecht (dir.), New German Dance Studies, Urbana, III., University of Illinois Press, 2012, p. 190-196.

10. Ibid.

11. Nell Andrew, Moving Modernism: The Urge to Abstraction in Painting, Dance, Cinema, Oxford, Oxford University Press, 2020.

12. Il y expose en même temps que Marc Chagall. Georg Brühl, Herwarth Walden und "Der Sturm ", Leipzig, Éditions Leipzig, 1983, p. 248.

13. Appelé selon les huit membres du groupe dont Emil Filla, Bohumil Kubišta, Antonín Procházka, etc., qui ont exposé ensemble en 1907 et 1908 ; Otakar Kubín ne participa qu'à la première exposition, voir Lamač, 1992, cité n. 2, p. 40-61.

14. Lahoda, 1996, cité n. 2, p 43-44.

15. Représentant de l'École de Paris dans l'entre-deuxguerres, il est connu pour sa peinture néo-classique. Voir Anna Pravdová, "Le néo-classicisme d'Otakar Kubín », dans Otakar Kubín / Othon Coubine. Boskovice - Paříz - Simiane, 1883-1969, cat. exp. (Boskovice, Muzeum Boskovicka - Galerie Otakara Kubína, 2019), Brno, Moravská galerie - Muzeum Boskovicka, 2019, n. p.

16. Le catalogue de la galerie Der Sturm contient les reproductions des quatre œuvres de Kubín sans donner leurs noms ; les titres d'œuvres exposées entre 1913 et 1916 à Prague, Berlin et Paris, dont il manque les reproductions, nous renseignent sur les sujets des tableaux sans qu'on puisse les rattacher exactement à une œuvre concrète. Voir Miroslav Lamač, Osma a Skupina výtvarných umělců, 1907-1917, Prague, Odeon, 1988, p. 473, fig. 535-538.

17. Otakar Kubín, Figure I, 1913-1914, Galerie nationale de Prague.

18. Les interprètes postérieurs ont qualifié les figures de Kubín de " dansantes » sans s'y attarder particulièrement. Voir Lamač, 1988, cité n. 16, p. 473 ; Lahoda, 1996, cité n. 2, p. 43-44.

19. Otakar Kubín, Le Music-hall Bobino, 1910, coll. privée, voir https://aloos.cz/cs/uspech/1336-otakar-kubinothon-coubine-music-hall-bobino.

20. Le danseur est représenté dans une posture légèrement penchée, un bras levé et l'autre tendu vers le bas, les paumes des mains renversées en arrière.

21. Isabelle Launay, À la recherche d'une danse moderne : Rudolf Laban, Mary Wigman, Paris, Chiron, 1996 ; Annie Suquet, L'Éveil des modernités. Une histoire culturelle de la danse (1870-1945), Pantin, Centre national de la danse, 2012, p. 382-397.

22. Rudolf von Laban, "Svět tanečníka », dans Ladislava Petišková (dir.), Čítanka světové choreografie 20. století, Prague, Konzervatoř Duncan Centre, 2005, p. 44-47. 
23. Une photographie de Laban en train de faire des exercices de tension (Spannungsübung), publiée dans son livre Die Welt des Tänzers. Fünf Gedankenreigen (Stuttgart, éditions W. Seifert, 1920), rappelle la posture de la figure de Kubín : https://portal.dnb.de/bookviewer/view/101433344X\#page/82/mode/2up.

24. Manquant de preuves concrètes, nous expliquons la ressemblance de l'œuvre plastique de Kubín avec la pensée chorégraphique de Laban par l'appartenance des deux artistes au même milieu spirituel et artistique, notamment à travers leurs relations au groupe munichois Der Blaue Reiter.

25. Wilhelm Worringer, Abstraktion und Einfühlung, Munich, R. Piper, 1908. Le livre avait une bonne réception auprès des cubistes tchèques et n'a fait que confirmer des tendances déjà présentes dans leur art. Voir David Filip, "Épilogue ", dans Wilhelm Worringer, Abstrakce a vcítění, Prague, Triáda, 2001, p. 131-148 ; Laban connaissait cette œuvre et la cite dans ses écrits, voir Evelyn Dörr, Lori Lantz, "Rudolf von Laban: "Founding Father" of Expressionist Dance ", dans Dance Chronicle, vol. 26, n 1, 2003, p. 12.

26. Voir les dessins de Rudolf von Laban de 1915 dans Macel, Lavigne, 2011, cité n. 8, p. 149.

27. De 1913 à 1918, Rudolf von Laban séjourne dans la colonie artistique de Monte Verità où il est marqué par l'ésotérisme et où l'esprit anarchique est très présent. Voir Suquet, 2012, cité n. 21, p. 391-397. Très peu informés sur la vie d'Otakar Kubín à cette période, on ne peut juger de ses aspirations spirituelles, ésotériques ou anarchiques que par les sujets de ses tableaux (voir Lamač, 1988, cité n. 16, p. 473).

28. Kubín expose en 1913, au Salon des Indépendants, L'Adorateur du Soleil (Lamač, 1988, cité n. 16, p. 473), tandis que Laban crée en 1917, à Monte Verità, L'Hymne au soleil (Suquet, 2012, cité n. 21, p. 393-396).

29. Lahoda, 1996, cité n. 2, p. 44.

30. Kubín représente Job qui bannit Dieu, L'Hermès mourant ou la déesse grecque Adrasteia. Voir Vojtěch Lahoda, "Otakar Kubín », dans Švestka, Vlček, 2006, cité n. 1, p. 176.

31. Il publie les cinquante exemplaires dans les deux langues. Otakar Kubín / Othon Coubine, Lidské bídy (Les Misères humaines), Paris, 1914. Le livre reçoit une bonne critique en France (voir « Expositions étrangères ", dans Paris-Journal, le 25 mai 1914).

32. Le poète tchéque Otto Klein, né en 1882 et mort dans les années 1980, traducteur de l'allemand et du français, vécut à Paris à partir des années 1910.

33. «[S]polečně prožívali radosti a strasti válečných let », voir Otakar Kubín, Les souvenirs, Archives de la Galerie nationale de Prague (AA 3716), s. d., fo 25.

34. Kubín aurait dû participer en tant que décorateur au film Le Cabinet du docteur Caligari, initialement confié à Fritz Lang et réalisé par la suite en 1919 par Robert Wiene avec Herman Warm, Walter Röhring et Walter Reimann. Voir Georges Sadoul, Dictionnaire des films (1965), Paris, Éditions du Seuil, 1990, p. 51. Petr Ingerle a récemment attiré l'attention sur ce fait dans « Od Osmy po Der Sturm: předválečná tvorba Otakara Kubína », dans Otakar Kubín / Othon Coubine, 2019, cité n. 15, n. p.
35. Otto Gutfreund, cat. exp. (Prague, Galerie nationale, 1995-1996), Prague, Galerie nationale, 1995 ; Jiří Šetlík, Otto Gutfreund: cesta ke kubismu, Prague, éditions Gallery, 2012.

36. Otto Gutfreund, "Plocha a prostor», 1913, dans id., Zázemí tvorby, Jiř́ Šetlík (éd.), Prague, Odeon, 1989, p. 227-231.

37. Voir la reproduction du carnet de 1910 dans ibid., fig. 20. Il appartient à Jan Štursa de créer sa statue monumentale en 1910-1911.

38. "Původní tanec byl vyjádřením tělesných žádostí, typickým př́kladem je tanec Salome, kde tanec je takřka př́mo pohlavním aktem, jako většina orientálních tanců. Realistické pohyby, uvedené v rytmus. " Voir Gutfreund, 1913, cité n. 36, p. 230.

39. «Tělesné hmotné znázornění je stejně silné svou výrazovou potencí jako orientální tanec », ibid.

40. "Tanečník inspiruje se hudbou a duševní stavy hudbou vzbuzené materializuje, přenáší je do skutečnosti, činí z nich zrakem chápatelné umění », ibid., p. 229.

41. Jan Mazurek, Metoda Jaques-Dalcrozova a česká hudební výchova, 1911-1938, Ostrava, Ostravská univerzita, Pedagogická fakulta, 2016.

42. En 1912, la revue Styl (vol. VI, p. 164), plate-forme de I'architecture cubiste, a publié l'un des textes de JaquesDalcroze sur la gymnastique rythmique. Sa méthode a eu, par ailleurs, une influence considérable au sein du mouvement gymnastique national Sokol.

43. La question du rythme a été traitée dans les textes des architectes Pavel Janák et Vlastislav Hofman. Voir Milena Lamarová, "Hledání moderního tvarosloví ", dans Český kubistický interiér, cat. exp. (Prague, musée des Arts décoratifs, 1976), Prague, musée des Arts décoratifs, 1976, p. 16-17.

44. Šetlík, 2012, cité n. 35, p. 104. Il s'agissait des compositeurs Václav Štěpán, Ladislav Vycpálek et Jaroslav Křička ; leurs textes et partitions musicales paraissaient dans Umělecký měsíčník.

45. Émile Jaques-Dalcroze, «La rythmique et la plastique animée ", dans Le Rythme, la musique, l'éducation, Lausanne / Genève, Éditions Foetisch / Institut Jaques-Dalcroze, 1965, cité dans Suquet, 2012, cité n. 21 , p. $174-175$.

46. Lahoda relie la déshumanisation de la figure chez Otto Gutfreund avec les expériences de la guerre qu'il passe dans un camp d'internement en France. Voir id., "La Métaphysique du vertige : les dessins d'Otto Gutfreund, 1913-1916 », dans Otto Gutfreund, 1995, cité n. 35, p. 123-134.

47. "Pohybující se plocha je tvořící se objem a není již více intelektem měřitelné formy; její funkci přejímá pohybující se plocha a socha není již zastavený čas, převedený v prostor, ale socha je výrazem plynulého dění, nepřetržitého pohybu, jehož rytmus je totožný s rytmem myšlenkového procesu tvưrčího, než se myšlenka ustálila v představu. [...] socha není již pevným konglomerátem objemů při postupném prohlížení zjistitelných, zkamenělým fragmentem času, ale nepřetržitým vlněním ploch, iluzí objemů », voir Gutfreund, «Plocha a prostor », 1913, cité dans Lamač, 1992, cité n. 2, p. 103. 
48. Otto Gutfreund connaissait L'Évolution créatrice (1907) d'Henri Bergson. Voir Gutfreund, 1913, cité n. 36, p. 254.

49. Alena Pomajzlová, Dynamismus českého umění desátých let, dans Id., (dir.), Rytmy + Pohyb + Světlo. Impulsy futurismu v českém umění, cat. exp. (Pilsen, Západočeská galerie, 2012-2013 / Brno, Moravská galerie, 2013), Řevnice, Arbor vitae-Pilsen, Západočeská galerie, 2012, p. 109-114.

50. «Pohyby tanečníka jsou postupné, jeden mizí nenávratně v druhém, divák přejímá jeden po druhém z těchto pohybů. Sochař přenechává tuto svalovou činnost tanečníka diváku, nutí diváka, nebo alespoň jeho oko, k obcházení, divák přijímá postupně obrazy vyvolané dílem. Nutí oko diváka k větším či menším skokům do hloubky, dle hloubkových relací sochy. » Gutfreund, 1913, cité n. 36, p. 228.

51. Rousseau, 2011, cité n. 8, p. 100.

52. Id., "O starém a novém umění », 1913-1914, dans Lahoda, 1995, cité n. 46, p. 123.

53. Jiří Kroha (1893-1974) Architekt, malír, designér, teoretik v proměnách umění 20. století, cat. exp. (Brno, Špilberk-Wroclaw, Musée de l'architecture, 2007), Brno, musée de la Ville, 2007.

54. Situé dans le quartier de la Vieille Ville de Prague.

55. Eva Bendová, Pražská kavárna, Prague, Verzone, 2017, p. 37-40.

56. Ibid., p. 39

57. Marcela Macharáčková, «Krohova malířská, sochařská a scénografická tvorba v letech 1913-1923 ", dans Jiř́ Kroha (1893-1974), 2007, cité n. 53, p. 34-43.

58. L'ensemble des esquisses du café Montmartre (19181919) se trouve au musée de la Ville de Brno dans le fonds Jiří Kroha, repr. dans ibid., fig. 17-20 et 41-46.

59. Monika Platzer, "Poznámky k ranému architektonickému dílu Jiřího Krohy z let 1911-1913 », ibid., p. 20-22.

60. Nous le rapprochons du Casino dansant (Berlin, 1920, Walter Würzbach et Rudolf Belling) et de la décoration des salles de la Curio-Haus (Hambourg, 1921, Friedrich Adler, Richard Luksch et Kurt F. Schmidt). Bendová le compare au projet non réalisé du Café Pittoresk d'Alexandre Rodtchenko et de Vladimir Tatlin (1917). Voir Bendová, cité n. 55, p. 39.

61. Jiří Kroha, "O prostoru architektonickém a jeho mezích », 1919-1920, dans Jiří Kroha (1893-1974), 2007, cité n. 53, p. 425-427.

62. «[S]tále se prostupující, střídající, obnovující [...] a tím právě trvající, živoucí », ibid., p. 425.

63. Pavel Janák, "Hranol a pyramida », dans Umělecký měsíčník, 1911-1912, no 1, p. 162-170.

64. Rostislav Švácha, "Expresionismus v české architektuře », dans Expresionismus a české umění (19051927), cat. exp. (Prague, Galerie nationale, 1994-1995), Prague, Galerie nationale, 1994, p. 208.

65. " [Vyjadřuje se] čistou, nekompromisní myšlenkou tvárnou », voir Kroha, 1919-1920, cité n. 61, p. 426.

66. "Tango v jeho secesně vláčných a dráždivě teskných tónech, formách, pohybech a gestech », voir Jiří Kroha, "Pražský Montmartre », lettre à un ami inconnu, 1970, archives Kroha, Jiří Kroha (1893-1974), 2007, cité n. 53, p. 450.

67. Rae Beth Gordon observe ce type de danse aux mouvements saccadés et désordonnés, inspirés par les épileptiques, dans des cafés-concerts parisiens. Voir Id., De Charcot à Charlot. Mises en scènes du corps pathologique (Standford, 2001), Rennes, Presses universitaires de Rennes, 2013, p. 91-108.

68. Egon Erwin Kisch, "Tragédie v Montmartru », dans L'almanach de Montmartre, 1913, p. 25.

69. "[Š]ílený, živelný, nesmyslný pohyb », voir Kroha, 1970, cité n. 66, p. 450.

70. «[R]oztočila, rozvírila a [...] rozbouřila », ibid.

71. "[O]dpor mládí [...] manifestací volnosti », ibid., p. 451.

72. "[J]arého, veselého, optimističtějšího », ibid., p. 450.

73. Par exemple, L'éventail cache I'hypocrisie ou Le miroir de la vraie face, voir Macharáčková, cité n. 57, p. 39.

74. Une photographie conservée au Musée national représente Josef Waltner déguisé en curé devant l'autel de Kroha, accompagné des serveuses du café qui représentaient les enfants de chœur. Voir Bendová cité n. 55, p. 39.

75. " [M]ámivé dojmy ekliptického víření nejasných tuch kol », voir Kroha, 1970, cité n. 66, p. 450.

76. " [K]de lidé více myšlenkově prožívali, než fyzicky utráceli », ibid.

77. « [V]elkého kosmického prostoru », dans Kroha, 1919-1920, cité n. 61, p. 425. 